\title{
Pattern of osteoarthritis among ethnic people residing hilly area: a cross sectional ethnic community based study
}

\begin{abstract}
Background: Osteoarthritis (OA) a common disease of aged population and one of the leading causesofdisability.Osteoarthritisaffectsspecificjointsmorethanothersincertainethnicgroups. Objective: The aim of this study was to assess the pattern of osteoarthritis among ethnic people in Khagrachari of Bangladesh.

Methods: This was a descriptive type of cross sectional community based study. A pretested structured questionnaire was used to collect the data among conveniently selected 200 samples. History of patient, X-ray and physical examination was used to diagnoses osteoarthritis. Data were entered and analyzed by using SPSS software. Verbal consent was taken from community Head as well as respondents before initiation of interview. Results: Maximum was in the age group of 51-60 years. Forty two percent were illiterate. About $30 \%$ were housewives and $32 \%$ were engaged in agriculture. Among the respondents $58 \%$ were from middle income group. Knee was the most affected (85\%) organ of osteoarthritis. Most of the respondents (42\%) suffered $>12$ month pain. Almost all of them feel pain during walking long distance. Conclusion: Most prevalent age to develop osteoarthritis was above 50 year. Most frequent affected joint was knee. Hill climbing may be aggravated factor
\end{abstract}

Keywords: pattern of osteoarthritis, ethnic people, hilly area
Volume 3 Issue I - 2015

\author{
Md Monoarul Haque,' Md Shah Billal \\ Masum, ${ }^{2}$ Monirul Haqe, ${ }^{2}$ Mohammad Shariful \\ Islam, ${ }^{3}$ Mohammad Shahadur Rahman, ${ }^{4}$ Jakir \\ Hossain Bhuiyan Masud, ${ }^{5}$ Syed Mohammed \\ Zakaria Faruq ${ }^{6}$ \\ 'Bangladesh Stroke Association, Bangladesh \\ ${ }^{2}$ Center for Neuro \& Orthopedic Rehabilitation (CNOR) \\ Bangladesh \\ ${ }^{3}$ Ibn Sina D. Lab, Bangladesh \\ ${ }^{4}$ USAID-DFID NHSDP Project, SSKS, Bangladesh \\ ${ }^{5}$ Center for Telehealth Services (CTS), Bangladesh \\ ${ }^{6} \mathrm{Al}$ Razi Islami Hospital, Bangladesh
}

\begin{abstract}
Correspondence: Md Monoarul Haque, Department of Community Nutrition, Faculty of Public Health, Bangladesh University of Health Sciences (BUHS), 125/I, Darus Salam, Mirpur, Dhaka-1216, Bangladesh, Tel 88 01915839550, Email monoarmunna@yahoo.com
\end{abstract}

Received: June 08, 20I5 | Published: June 24, 2015

\section{Introduction}

Osteoarthritis (OA) is one of the most prevalent conditions resulting to disability particularly in elderly population. $\mathrm{OA}$ is the most common articular disease of the developed world and a leading cause of chronic disability, mostly as a consequence of the knee OA and/or hip OA. ${ }^{1}$ The economic costs of OA are high, including those related to treatment, for those individuals and their families who must adapt their lives and homes to the disease, and those due to lost work productivity. ${ }^{2}$ The prevalence of OA increases with age and generally affects women more frequently than men. ${ }^{3}$ It has been estimated that the percentage of people aged 65 years or over in Asia will more than double in the next two decades, from $6.8 \%$ in 2008 to $16.2 \%$ in 2040 . In most of the developed world, demographic change was a gradual process following steady socioeconomic growth over several decades. In many Asian countries, the change is being compressed into two or three decades. For example, during the period of 2008-2040, it is estimated that Singapore will increase the proportion of people aged 65 and over by $316 \%$, India by $274 \%$, Malaysia by $269 \%$, Bangladesh by $261 \%$ and the Philippines by $256 \%{ }^{4}$ Apart from aging, there is much evidence from mostly North American or European cohorts that obesity or heavy occupational physical activity, such as carried out by many people in rural communities within the Asian region, are clear risk factors for symptomatic knee and hip OA. ${ }^{5}$ Although ample studies have been conducted on knee osteoarthritis worldwide, but scanty data is available in ethnic communities in Bangladesh.

\section{Methodology}

It was a descriptive type of cross sectional study. Patients were selected from different clinics/hospitals/physiotherapy center attending for treatment in Khagrachari sadar upazilla. All suspected cases of OA were included in the study. Non probability convenient sampling was used to collect data. Sample size was 200 and all were Tripura. The duration of the study was 6 months and conducted from December 2014 through May 2015. Data were collected by pre tested structured questionnaires and in face to face interview. Diagnosis of osteoarthritis was confirmed by medical records, radiological examination as well as physical examination. After collection of data, all responses checked for their completeness, correctness and internal consistency in order to exclude missing or inconsistent data. Corrected data was entered into the computer. The data was analyzed by using the statistical software namely SPSS (Statistical Package for Social Science).

\section{Results}

Maximum were in the age group of 51-60 years. Male and female distribution was $54 \%$ and $46 \%$. Forty two percent were illiterate. About $30 \%$ were housewives and $32 \%$ were engaged in agriculture. Among the respondents $35 \%, 58 \%$ and $7 \%$ were from lower income group $(<10000), 58 \%$ middle income group (10001-20000) and 5\% high income group $(>20000)$. All were Tripura (Table $1 \& 2)$ (Figures $1-3)$.

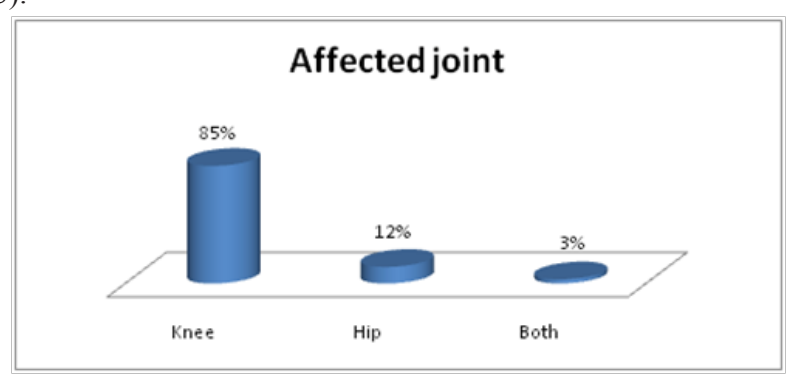

Figure I Affected joint $(n=200)$. 


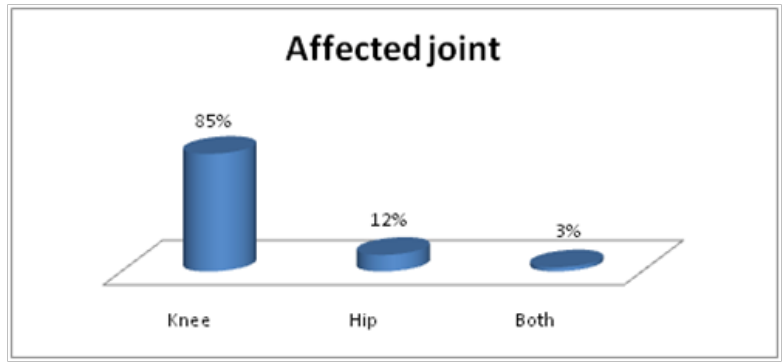

Figure 2 Duration of pain $(n=200)$. More than half $(54 \%)$ of respondents did vigorous hill climbing activity followed by moderate hill climbing activity (29\%) and less hill climbing activity (I7\%).

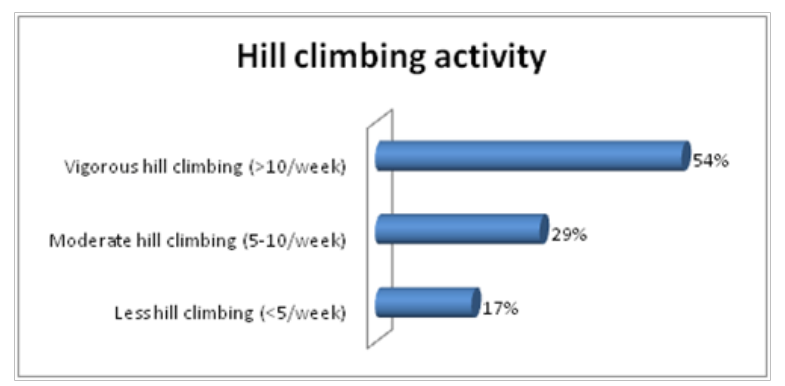

Figure 3 Hill climbing activity of respondents $(n=200)$.Almost all of them feel pain during walking long distance. About $95 \%$ faced difficulty in toileting and $60 \%$ were unable to climb hill.

Table I Socio-demographic characteristics of respondents $(n=200)$

\begin{tabular}{|c|c|c|}
\hline Variables & Number & Percentage \\
\hline \multicolumn{3}{|l|}{ Age (in years) } \\
\hline $21-30$ & 8 & 4 \\
\hline $31-40$ & 18 & 9 \\
\hline $41-50$ & 34 & 17 \\
\hline $51-60$ & 80 & 40 \\
\hline$>60$ & 60 & 30 \\
\hline \multicolumn{3}{|l|}{ Sex } \\
\hline Male & 108 & 54 \\
\hline Female & 92 & 46 \\
\hline \multicolumn{3}{|l|}{ Education } \\
\hline No schooling & 84 & 42 \\
\hline Primary & 52 & 26 \\
\hline Secondary & 50 & 25 \\
\hline $\begin{array}{l}\text { Higher-Secondary \& } \\
\text { Above } \\
\text { Occupation }\end{array}$ & 14 & 7 \\
\hline Housewife & 60 & 30 \\
\hline Agriculture & 64 & 32 \\
\hline Business & 52 & 26 \\
\hline Others & 24 & 12 \\
\hline \multicolumn{3}{|l|}{ Ethnicity } \\
\hline Tripura & 200 & 100 \\
\hline \multicolumn{3}{|c|}{ Monthly Income (BDT) } \\
\hline Lower Income & 70 & 35 \\
\hline Middle Income & 116 & 58 \\
\hline High Income & 14 & 7 \\
\hline
\end{tabular}

Knee was the most affected (85\%) organ of osteoarthritis followed by hip (I2\%) and both knee \& hip (3\%).
Table 2 Problem facing due to osteoarthritis

\begin{tabular}{lll}
\hline Variables & Number & Percentage \\
\hline Difficulty in toileting & 190 & 95 \\
Difficulty in farming & 64 & 32 \\
Feeling pain during walking long distance & 200 & 100 \\
Unable to climb hill & 120 & 60 \\
\hline
\end{tabular}

\section{Discussion}

Osteoarthritis (OA), the most common form of arthritis, can affect many different joints in the body, and may be silent (found on $\mathrm{x}$-rays only) or symptomatic (causing symptoms like pain, aching, or stiffness on most days). These investigators wondered if there might be a pattern (called phenotype) of which joints are affected. A study examined whether the patterns of symptomatic OA involving 4 joint sites (hands, knees, hips, and lumbosacral spine) might differ by race and sex. In a sample of 1,650 participants in the Johnston County Osteoarthritis Project (age 45 and older; 36\% men; 32\% African American) analysts found that overall $11 \%$ had symptomatic hip OA, $13 \%$ had symptomatic hand OA, 25\% had symptomatic knee $\mathrm{OA}$, and $28 \%$ had symptomatic lumbosacral spine OA. When they examined patterns of multiple joint symptomatic OA, they found that women more often had hand involvement, men more often had lumbosacral spine involvement, African Americans more often had knee involvement, and Caucasians more often had hand involvement. These differences may need to be considered when researchers are defining multijoint, or generalized, OA. ${ }^{6}$ The present study found that knee was the most affected (85\%) organ of osteoarthritis followed by hip (12\%) and both knee \& hip (3\%). Those who did moderate type of activity, $63 \%$ of them suffered from osteoarthritis followed by sedentary activity $(32 \%)$ and hard worker $(5 \%) .^{7-9}$ The present study found more than half $(54 \%)$ of respondents did vigorous hill climbing activity. Most of the patients in the study ${ }^{10}$ were in the age group of 40 to 59 years. There was a significant positive association between age, radiographic severity, and pain severity. This finding supports the fact that $\mathrm{OA}$ is a common health problem in middle and old age and this is consistent with previous studies. ${ }^{11,12}$ Age is considered as a strong risk factor for KOA, but the underlying mechanism remains obscure. ${ }^{13,14}$ Whereas tensile stiffness of knee articular cartilage and proteoglycan content decrease with age ${ }^{13}$ advanced glycation end products and cartilage turnover markers increase with age. ${ }^{14}$ These biomechanical and biochemical changes in articular cartilage may have a role in age related OA, but age related morphological alterations in articular cartilage and subchondral bone are potential further explanations for OA. But present study found that most of the patients (40\%) were suffering from osteoarthritis in 51-60 years age group.

\section{Conclusion}

Most prevalent age to develop osteoarthritis was above 50 year. Most frequent affected joint was knee. Hill climbing may be aggravated factor.

\section{Acknowledgment}

The authors express their sincere thanks to all the patients of this study. No external funding was provided for this study. This was a group work. Special thanks to Nantu Bikash Tripura for extensive help.

\section{Conflicts of interest}

Authors declare there is no conflicts of interest. 


\section{References}

1. BadiaA.Arthroscopy of the trapeziometacarpal and metacarpophalangeal joints. J Hand Surg Am. 2007;32(5):707-724.

2. Grazio S, Balen D. Obesity: Risk factor and predictors of osteoarthritis. Lijec Vjesn. 2009;131(1-2):22-26.

3. Altman RD. Early management of osteoarthritis. Am J Manag Care. 2010;16 Suppl Management: S41-S47.

4. Kinsella K, He W. An Ageing World: 2008. U.S. Census Bureau, Washington DC, USA: 2009.

5. Jensen LK. Knee osteoarthritis: influence of work involving heavy lifting, kneeling, climbing stairs or ladders, or kneeling/squatting combined with heavy lifting. Occup Environ Med 2008;65(2):72-89.

6. Jensen LK. Knee osteoarthritis: influence of work involving heavy lifting, kneeling, climbing stairs or ladders, or kneeling/squatting combined with heavy lifting. Occup Environ Med. 2008;65(2):72-89.

7. Nelson AE, Golightly YM, Renner JB, et al. Brief report: differences in multijoint symptomatic osteoarthritis phenotypes by race and sex: the johnston county osteoarthritis project. Arthritis Rheum. 2013;65(2):373-377.

8. Dieppe PA. Clinical features and diagnostic problems in osteoarthritis In: Klipple JH, Dippe PA, editors. Practical Rheumatology. Mosby publishers, BMJ; 1995:141-156.
9. Felson DT. The epidemiology of knee osteoarthritis: results from the framingham osteoarthritis study. Semin Arthritis Rheum. 1990;20(3 Suppl 1):42-50.

10. Powell A, Teichtahl AJ, Wluka AE, et al. Obesity: a preventable risk factor for large joint osteoarthritis which may act through biomechanical factors. Br J Sports Med. 2005;39(1):4-5.

11. Ziad M Hawamdeh, Jihad M Al-Ajlouni. The Clinical Pattern of Knee Osteoarthritis in Jordan: A Hospital Based Study. Int J Med Sci. 2013;10(6):790-795.

12. Altman RD. Criteria for classification of clinical osteoarthritis. $J$ Rheumatol. 1991;27:10-12.

13. Dequeker J, Dieppe PA. Disorders of bone cartilage and connective tissue. In: Klippel JH, Dieppe PA, editors. Rheumatology. 2nd ed. London, UK: Mosby publishers; 1998:24-25.

14. Felson DT, Lawrence RC, Dieppe PA, et al. Osteoarthritis: new insights. Part 1: the disease and its risk factors. Ann Intern Med. 2000;133(8):635646.

15. Kempson GE. Age-related changes in the tensile properties of human articular cartilage: a comparative study between the femoral head of the hip joint and the talus of the ankle joint. Biochim Biophys Acta. 1991;1075(3):223-230 